\title{
Estudo de direções de chegada de raios cósmicos de altíssima energia através de
} simulações de Monte Carlo.

\section{Luísa Pires Ferreira*, Thaina M.B. Pezzuto, Danelise de Oliveira Franco, Carola Dobrigkeit}

\section{Resumo}

O método de Monte Carlo é um método computacional formalizado com o intuito de determinar e resolver problemas utilizando uma gama enorme de variáveis aleatórias. Neste estudo tal método foi utilizado para simular as variáveis das direções de chegada de raios cósmicos de altíssima energia, partindo de uma hipótese de isotropia. Foi possível aplicar o método em diferentes situações, tais como um detector de placas paralelas ou um mapeamento do céu seguindo a exposição do Observatório Pierre Auger.

\section{Palavras-chave:}

Método de Monte Carlo, raios cósmicos, coordenadas equatoriais.

\section{Introdução}

Um evento é dito aleatório ou não determinístico, quando não é possível conhecer as condições iniciais de um fenômeno, ou seja, quando este não segue padrões ou regras que nos permitam fazer previsões determinísticas sobre o comportamento do evento.

Um raio cósmico é uma partícula penetrante subatômica, como um próton ou um núcleo de átomo, que chega na Terra e entra na atmosfera. Essa partícula pode interagir com as demais moléculas na atmosfera e desencadear o que chamamos de chuveiro atmosférico.

A direção de chegada de um raio cósmico na Terra é determinada pelos ângulos zenital $(\Theta)$ e azimutal $(\Phi)$. Porém, a direção de chegada não é única e os raios cósmicos chegam com uma distribuição que é aproximadamente isotrópica. Tais ângulos são variáveis aleatórias, tornando a direção de chegada de um raio cósmico uma grandeza aleatória.

O método de Monte Carlo utiliza números aleatórios associados a variáveis para a realização de sucessivas simulações [1]. Assumindo isotropia nas direções dos raios cósmicos, são associados números aleatórios aos ângulos $\Phi$ e $\theta$, a fim de simular direções isotropicamente distribuídas no céu, imitando as direções de chegada dos raios cósmicos.

\section{Resultados e Discussão}

Uma das simulações mais didáticas realizadas foi a exemplificação do sorteio dos ângulos azimutais e zenitais com o propósito de simular a direção dos raios cósmicos que chegam na Terra isotropicamente. Para tal objetivo, supusemos que os ângulos $\Phi$ e $\Theta$ são correspondentes à ascensão reta e declinação sobre a esfera celeste.

Partimos da definição de um ângulo sólido, uma área infinitesimal sobre uma esfera (neste caso, uma esfera celeste de raio unitário) dada por:

$$
d \Omega=\sin \theta d \theta d \Phi .
$$

Associando ambos $\theta$ e $\Phi$ a dois números aleatórios uniformemente distribuídos entre 0 e 1 que chamaremos de $u^{*}$ e $v^{*}$, temos o caminho da simulação que queremos para gerar $\Theta^{*}$ e $\Phi^{*}$. Primeiro, temos que garantir que os ângulos estarão no intervalo desejado por meio de uma constante de normalização (dada por $A, B$ e $C$ nas equações 2 e 3). Encontramos, então a constante $\mathrm{A}=B x C$, tal que a integral em (2) nos dá:

$$
\int d \Omega=A \int_{0}^{2 \pi} d \Phi \int_{0}^{\pi} \sin \theta d \theta=1
$$

Em seguida, encontramos os ângulos $\Theta^{*}$ e $\Phi^{*}$, a partir de:

$$
B \int_{0}^{\Phi^{*}} d \Phi=u^{*} e C \int_{0}^{\Theta^{*}} \operatorname{sen} \theta d \theta=v^{*}
$$

Assim, cada valor de variável aleatória vai ser relacionado a um valor de ângulo, e cada par de ângulos corresponderá a uma direção de um chuveiro atmosférico e, portanto, a um ponto no mapa celeste. Para melhor visualização, essa simulação foi repetida para $10^{3}$ pares de ângulo, como pode ser visto na Figura 1.

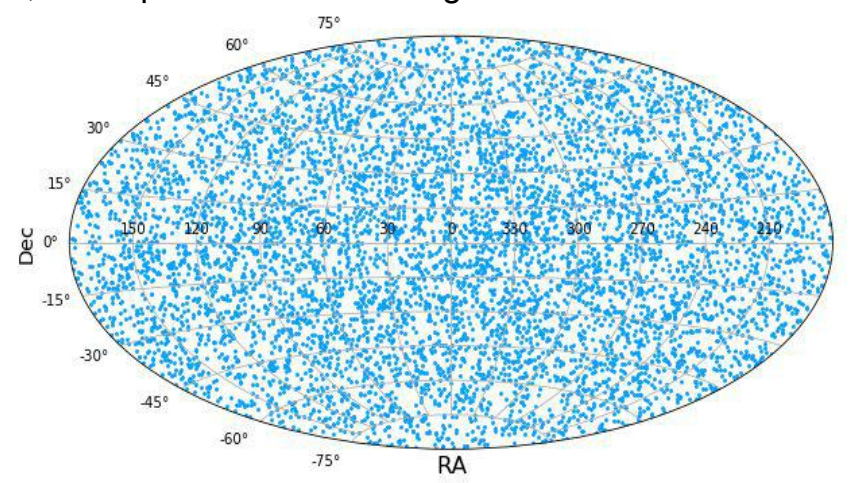

Figura 1: Mapa de direções de raios cósmicos em coordenadas equatoriais.

Dado o grande espectro de aplicações do Método de Monte Carlo, neste projeto foi possível trabalhar com diversas simulações de grandezas físicas no âmbito de eventos não-determinísticos, tais como a simulação de um detector de raios cósmicos para verificação de sua eficiência, de acordo com a sua geometria.

\section{Conclusões}

A pesquisa ainda está em andamento e, portanto, os dados ainda não são conclusivos. Ao final, iremos comparar direções simuladas com direções de raios cósmicos reais, a fim de testar se a hipótese adotada na simulação permite descrever os dados reais.

[1]Bittencourt. Hélio Radke.. CONTRIBUIÇÕES PARA O ENSINO DA DISTRIBUIÇÃO NORMAL OU CURVA DE GAUSS EM CURSOS DE GRADUAÇÃO.II SEMINARIO INTERNACIONAL DE PESQUISA EM EDUCAÇÃO MATEMATICA, p.3-4.. Disponível em: https://www.researchgate.net. Acesso em Jul. 2019. 